\title{
The Preferred Ring-Tautomeric Form of a Bicyclic $\gamma$-Ketocarboxylic Acid: An Equilibrium Driven by Relief of Angular Hybridization Strain
}

\author{
Jesse K. Wong, Roger A. Lalancette* and Hugh W. Thompson
}

Carl A. Olson Memorial Laboratories, Department of Chemistry, Rutgers University, Newark, NJ 07102, USA

\begin{abstract}
Carboxy-2-endo-methyl-7-oxobicyclo[2.2.1]heptane exists preferentially in its closed, ringtautomer form, the tricyclic lactol $\left(\mathrm{C}_{9} \mathrm{H}_{12} \mathrm{O}_{3}\right)$, which aggregates catemerically by forming hydroxyl-to-carbonyl hydrogen bonds $\left[\mathrm{O} \cdots \mathrm{O}=2.7667(16) \AA, \mathrm{O}-\mathrm{H} \cdots \mathrm{O}=170^{\circ}\right]$ among molecules screw related in $b$. This ring-chain equilibrium is driven by relief of angular strain at the 7-ketone, whose origin is the ketone's $\mathrm{sp}^{2}$ hybridization vs. the angle enforced by the bicyclic system. In the analogous compound with transposed functional groups, the equilibrium favors the keto acid, which is easily isolated.
\end{abstract}

Keywords: Hydrogen bonding, angle strain, keto carboxylic acids, ring-chain tautomerism, X-ray crystallography.

\section{INTRODUCTION}

Our continued interest in the X-ray structures of crystalline ketocarboxylic acids involves the factors controlling their hydrogen bonding. The simultaneous presence of one donor with two potential receptors leads to a total of five basic patterns that have thus far been found to characterize their H-bonding. Most commonly, as in simple acids, carboxyl groups are paired by mutual hydrogen bonding without ketone participation, to form the common acid-to-acid dimer motif. Less frequently, a chain (catemer) is produced by repetition of an intermolecular carboxyl-to-ketone hydrogen bond. Relatively rare arrangements involve internal hydrogen bonds [1], acid-to-ketone dimers [2] and carboxyl catemers [3].

Many of the $\gamma$ - and $\delta$-ketocarboxylic acids we study are capable of ring-chain tautomerism [4, 5] and several are known to exist predominantly or exclusively in the closed, lactol form, sometimes referred to as the "pseudoacid" [6-10]. A search of the X-ray literature (Cambridge Structural Database, Version 5.27, update of May, 2006) [11] reveals some 63 examples of keto-acid lactol structures, of widely varying degrees of complexity. About $90 \%$ of these are derived from what are formally $\gamma$-keto acids, which yield five-membered lactols, the size known to be most favorable for such rings $[4,12]$.

In order to examine issues controlling the position of equilibrium in such cases of ring-chain tautomerism, we have determined the X-ray structure of compound $\mathbf{1}$, a keto acid known to exist entirely in the closed lactol form.

\section{MATERIAL AND METHODS}

\section{Crystallization}

Compound 1 was prepared as described by Thompson et al. [7]. Crystals suitable for X-ray analysis were produced

*Address correspondence to this author at the Rutgers University, Department of Chemistry, Newark NJ 07102, USA; Tel: 973-353-5646; Fax: 973353-1264; E-mail: rogerlal@andromeda.rutgers.edu from hexane/diisopropyl ether, m.p. $384 \mathrm{~K}$. The solid-state $(\mathrm{KBr})$ infrared spectrum displays intense peaks for associated $\mathrm{OH}$ at 3225 and for $\mathrm{H}$-bonded $\mathrm{C}=\mathrm{O}$ at $1724 \mathrm{~cm}^{-1}$. Although an IR spectrum of an ether solution revealed no detectable concentration of the keto-acid form, the keto methyl ester could be produced by direct reaction of such a solution with diazomethane.

\section{X-Ray Data Collection and Processing}

X-ray diffraction data were collected on a Bruker Apex2 diffractometer [13], using monochromatic $\mathrm{CuK} \alpha$ radiation of $1.54178 \AA$ at $100 \mathrm{~K}$ using a stream of nitrogen gas. The crystal, a clear, colorless parallelepiped $(0.24 \times 0.17 \times 0.15 \mathrm{~mm})$, was mounted in a nylon Cryoloop using Paratone-N to hold it in place. Crystallographic Data: Formula $=\mathrm{C} 9 \mathrm{H} 12 \mathrm{O} 3$, Molecular weight $=168.19$, monoclinic, $\mathrm{P} 21 / \mathrm{n}$ (no. 14), a = $6.4030(5) \AA, \mathrm{b}=10.6590(3) \AA, \mathrm{c}=12.1023(3)$, alpha $=90^{\circ}$ , beta $=102.083(1)^{\circ}$, gamma $=90^{\circ}, \mathrm{V}=807.68(4) \AA 3, \mathrm{Z}=$ 4 , $\mathrm{D}$ calcd $=1.383 \mathrm{~g} \mathrm{~cm}-3, \mathrm{mu}=0.856 \mathrm{~mm}-1,4350$ reflections measured, 1465 reflections independent, $\mathrm{R}$ int = $0.0516, \mathrm{R}(\mathrm{F})=0.0506$, wR $2=0.1360$, goodness of fit $=$ 1.059 , and $\mathrm{T}=100.0(1) \mathrm{K}$.

The data were processed using the SHELXTL program package [14]. All of the experimental data are in the X-ray crystallographic files in CIF format and have been deposited with the Cambridge Structural Database as file CCDC 685388. The material can be obtained, free of charge, on application to CCDC, 12 Union Road, Cambridge CB2 1EZ, UK. (fax: +44 1223336033 or email: deposit@ccdc.cam.ac.uk).

\section{RESULTS AND DISCUSSION}

(士)-2-exo-Carboxy-2-endo-methyl-7-oxobicyclo[2.2.1]heptane exists preferentially, even in solution, as the ringclosed tricyclic lactol 1 (see Fig. (1)), the form in which it crystallizes as well. 7-Oxobicyclo[2.2.1] heptanes have internal carbonyl angles at C7 of $97-98^{\circ}$ [15], and are thus strained by some $22-23^{\circ}$ relative to the natural carbonyl angle. This destabilizes $\mathrm{sp}^{2}$ relative to $\mathrm{sp}^{3}$ hybridization and renders a C7 carbonyl particularly susceptible to addition, 
strongly favoring 1 in this equilibrium, even though the result does not improve the C1-C7-C4 angle in an absolute sense $\left[\mathrm{C} 1-\mathrm{C} 7-\mathrm{C} 4=96.01(11)^{\circ}\right]$. By contrast, 2oxonorbornanes, with about $10^{\circ}$ less strain in their internal carbonyl angles [16-19], are far less susceptible to carbonyl addition. Thus, the case of $\mathbf{1}$ may be dramatically contrasted with that of 7-syn-carboxynorbornan-2-one, in which these two functions are merely transposed, and in which the ketoacid form predominates and is easily isolatable [20,21].

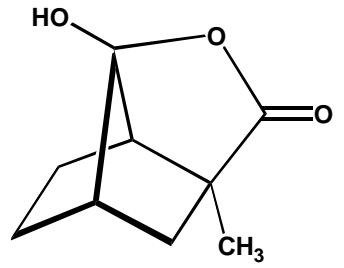

Fig. (1). The molecular structure of compound $\mathbf{1}$.

Fig. (2) shows the asymmetric unit, whose only significant rotation involves the hydroxyl group; this is turned so that the $\mathrm{H} 3-\mathrm{O} 3-\mathrm{C} 7-\mathrm{O} 2$ torsion $=87^{\circ}$. In simple bicyclo[2.2.1]heptane systems, the $\mathrm{C} 2-\mathrm{C} 1-\mathrm{C} 7$ angle is typically $100-103^{\circ}[13-17,22]$. In $\mathbf{1}$, because of the compression imposed by lactol formation, this angle is $92.89(11)^{\circ}$, and this in turn produces a twist in the $\mathrm{C} 2-\mathrm{C} 3$ bond that mitigates eclipsing strain between the $\mathrm{C} 2$-methyl and the endo- $\mathrm{H}$ at $\mathrm{C} 3$ $\left(\mathrm{H} 3 \mathrm{~A}-\mathrm{C} 3-\mathrm{C} 2-\mathrm{C} 9=-34^{\circ}\right)$. The analogous torsion on the other side of the system, H6A-C6-C5-H5B, is $-12^{\circ}$.

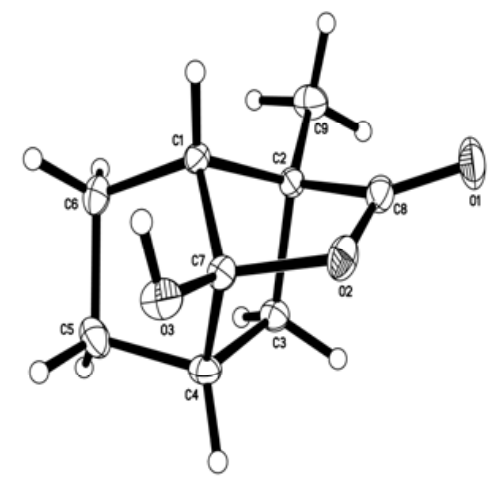

Fig. (2). The asymmetric unit of 1 with its numbering, which follows that of the parent keto acid. Displacement ellipsoids are set at the $40 \%$ probability level.

Fig. (3) illustrates the packing arrangement and the $\mathrm{H}-$ bonding scheme for $\mathbf{1}$. As in other simple lactols, the $\mathrm{H}$ bonding is catemeric, proceeding from the hydroxyl of one molecule $(\mathrm{O} 3)$ to the carbonyl $(\mathrm{O} 1)$ of a neighbor $[\mathrm{O} 3 \cdots \mathrm{O} 1=$ $\left.2.7667(16) \AA, \mathrm{O} 3-\mathrm{H} 3 \cdots \mathrm{O} 1=170^{\circ}\right]$, in this case one screwrelated in $b$ (see Table $\mathbf{1}$ ).

This pattern arises out of the diminished repertoire of $\mathrm{H}$ bonding modes that result from the presence in the lactol form of only one H-bond donor and one acceptor. Each of the cell's four asymmetric units participates in a separate $\mathrm{H}$ bonding chain, creating two parallel sets of counterdirectional pairs, each pair being centrosymmetrically related about $1 / 2,1 / 2,1 / 2$.

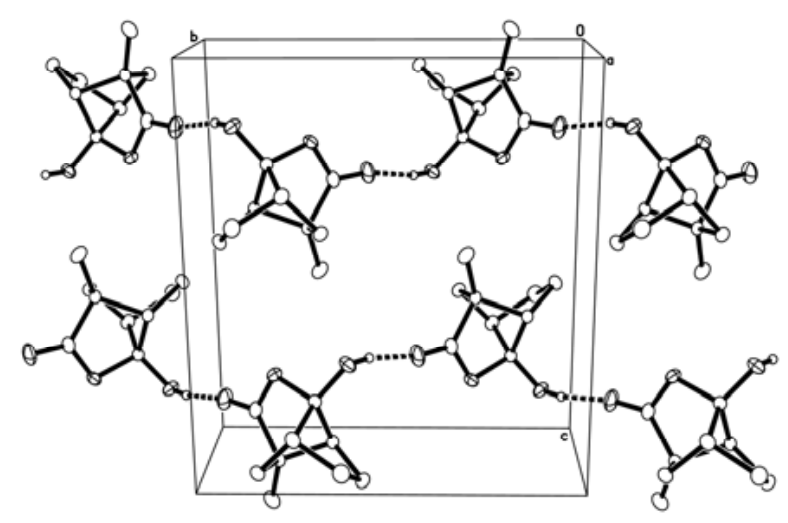

Fig. (3). A partial packing diagram with extracellular molecules, illustrating the H-bonding arrangement for 1. All carbon-bound hydrogens are removed for clarity. Displacement ellipsoids are set at the $40 \%$ probability level.

We characterize the geometry of $\mathrm{H}$ bonding to carbonyls using a combination of the $\mathrm{H}^{\cdots} \mathrm{O}=\mathrm{C}$ angle and the $\mathrm{H}^{\cdots} \mathrm{O}=\mathrm{C}-$ $\mathrm{X}$ torsion angle. These describe the approach of the $\mathrm{H}$ atom to the $\mathrm{O}$ in terms of its deviation from, respectively, $\mathrm{C}=\mathrm{O}$ axiality (ideal $=120^{\circ}$ ) and planarity with the carbonyl (ideal $=0^{\circ}$ ). In 1, these approach angles for the hydrogen bond are $165 \& 35^{\circ}$, respectively, indicating significant departures, imposed by restraints other than H-bonding, from the ideal packing arrangement.

Within the 2.6- $\AA$ range surveyed for non-bonded intermolecular $\mathrm{C}-\mathrm{H} \cdots \mathrm{O}$ packing interactions [23], one close contact was found $(2.54 \AA)$ from $\mathrm{H} 3 \mathrm{~B}$ to $\mathrm{O} 3$ in an adjacent molecule (see Table 1). Using compiled data for a large number of $\mathrm{C}-\mathrm{H} \cdots \mathrm{O}$ contacts, Steiner and Desiraju [24] find statistical directionality even as far out as $3.0 \AA$ A, and conclude that these are legitimately viewed as "weak hydrogen bonds", with a greater contribution to packing forces than simple van der Waals attractions.

Table 1. Hydrogen Bonding and Close Contact $\left(\AA{ }^{\circ},{ }^{\circ}\right)$

\begin{tabular}{|c|c|c|c|c|}
\hline $\mathbf{D}($ onor $)-\mathbf{H}^{\cdots} \boldsymbol{A}($ (cceptor $)$ & D-H & $\mathbf{H} \cdots \mathbf{A}$ & D-A & D-H $\cdots A$ \\
\hline $\mathrm{O} 3-\mathrm{H} 3 \cdots \mathrm{O}^{\mathrm{a}}$ & 0.84 & 1.93 & $2.7667(16)$ & 170 \\
\hline $\mathrm{C} 3-\mathrm{H} 3 \mathrm{~B}^{\cdots} \mathrm{O} 3^{\mathrm{b}}$ & 0.99 & 2.54 & $3.4404(19)$ & 151 \\
\hline
\end{tabular}

symmetry codes: ${ }^{\mathrm{a}} \mathrm{x}+5 / 2, \mathrm{y}+1 / 2,-\mathrm{z}+1 / 2{ }^{\mathrm{b}}-\mathrm{x}+3 / 2, \mathrm{y}-1 / 2,-\mathrm{z}+1 / 2$.

\section{CONCLUSIONS}

The X-ray crystal structure of compound $\mathbf{1}$ has been determined and has been shown to contain the ketol function that is favored, relative to the open-chain alternative, by angle strain in the keto acid.

\section{ACKNOWLEDGEMENTS}

The authors acknowledge support by NSF-CRIF Grant No. 0443538. HWT is grateful to Professor Gree Loober Spoog for helpful consultations. 


\section{REFERENCES}

[1] Coté ML, Lalancette RA, Thompson HW. 1-Carboxyfluorenone: an Intramolecularly Hydrogen-Bonded $\gamma$-Keto Acid. Acta Cryst C 1996; 52: 1535-7.

[2] Newman JM, Papadakis MM, Thompson HW, Lalancette RA. 1'Acetylferrocene-1-carboxylic acid: an instance of hydrogen bonding in the rare dimeric acid-to-ketone mode. Acta Cryst C 2002; 58 : m89-91.

[3] Dufort MD, Davison M, Lalancette RA, Thompson HW. 3-Oxo5 $\beta$-24-norcholanic acid: acid-to-acid hydrogen-bonding catemers employing the rare anti carboxyl conformation in the aggregation of a steroid keto acid. Acta Cryst C 2007; 63: o646.

[4] Jones PR. Ring-Chain Tautomerism. Chem Rev 1963; 63: 461-87.

[5] Valters RE, Flitsch W. Ring-Chain Tautomerism New York: Plenum Press 1985.

[6] Chadwick DJ, Dunitz JD. Crystallographic and Spectroscopic Study of the Keto-acid-Hydroxy-lactone Isomerisation Path. J Chem Soc PerkinTrans 2 1979; 276-84.

[7] Thompson HW, Wong JK, Lalancette RA, Boyko JA, Robertiello AM. Synthesis of 2,2-Disubstituted 7-Methylene-norbornanes with 2-Exo Functionality by Diels-Alder Reaction of 5,5Dimethoxytetrachlorocyclopentadiene. J Org Chem 1985; 50: 2115-21.

[8] Dobson AJ, Gerkin RE. 2-Acetylbenzoic Acid: Phthalide Form. Acta Cryst C 1996; 52: 3078-81.

[9] Valente EJ, Fuller JF, Ball JD. Pseudoacids. I. 4-and 5-Oxoacids. Acta Cryst B 1998; 54: 162-73.

[10] Papadakis MM, Pavon JA, Lalancette RA, Thompson HW. The epimeric 9-oxobicyclo[3.3.1]-nonane-3-carboxylic acids: hydrogen-bonding patterns of the endo acid and the lactol of the exo acid. Acta Cryst C 2003; 59: o167-70.

[11] Allen FH. The Cambridge Structural Database: a quarter of a million crystal structures and rising. Acta Cryst B 2002; 58: 380-8.

[12] Soffer MD, Stewart RA, Cavagnol JC, Gellerson HE, Bowler EA. Syntheses in the Direction of Morphine. II. Some Intermediates and Model Compounds. J Am Chem Soc 1950; 72: 3704-9.

[13] Bruker AXS Inc. APEX 2 Version 2.0-2 2006. Madison WI, USA: Bruker AXS Inc.
[14] Sheldrick GM. SHELXTL Version 6.14 2004. Madison WI, USA: Bruker AXS Inc.

[15] Wong JK, Macalintal RAR, Brunskill APJ, Lalancette RA, Thompson HW. 7-Oxobicyclo[2.2.1] heptane-1-carboxylic acid and ( \pm )-7oxobicyclo[2.2.1] hept-5-ene-2-endo-carboxylic acid: hydrogen bonding in two norbornyl keto acids. Acta Cryst C 2000; 56: 371-3.

[16] Lalancette RA, Vanderhoff PA, Thompson HW. Catemeric Hydrogen Bonding in $(+)$ and $( \pm)$-endo-Camphorcarboxylic Acid. Acta Cryst C 1991; 47: 132-6.

[17] Lalancette RA, Coté ML, Thompson HW. Hydrogen-Bonding Pattern of a Bicyclic $\gamma$-Keto Acid: (-)-anti-Isoketopinic Acid. Acta Cryst C 1997; 53: 370-2.

[18] Lalancette RA, Coté ML, Smith WJ III, et al. (+)-and ( \pm )-ketopinic acid: hydrogen-bonding patterns in a $\beta$-keto acid in its enantiomeric and racemic forms and enantiomeric disordering in the racemate. Acta Cryst C 1999; 55: 1600-5.

[19] Thompson HW, Coté ML, Lalancette RA. (+)-Camphoracetic acid: catemeric hydrogen bonding in a $\gamma$-keto acid. Acta Cryst C 2004; 60: o727-9.

[20] Beckmann S, Geiger H. Zur Kenntnis der bei der Hydratisierung von Bicyclo[1.2.2]-hepten-carbonsäuren entstehenden Lactone. Chem Ber 1961; 94: 48-58.

[21] Nickon A, Kwasnik HR, Mathew CT, Swartz TD, Williams RO, DiGiorgio JB. Synthesis and Structure Proof of C-2 and C-4 Monofunctionalized Brexanes and Brendanes. J Org Chem 1978; 43 3904-16.

[22] Brunskill APJ, Lalancette RA, Thompson HW. ( \pm )-3-Benzoylbicyclo[2.2.1] heptane-2-carboxylicacid: structures and hydrogenbonding patterns of the di-endo and the 2-endo-3-exo isomers. Acta Cryst C 1999; 55: 1905-8.

[23] Steiner T. Unrolling the hydrogen bond properties of $\mathrm{C}-\mathrm{H} \cdots \mathrm{O}$ interactions. Chem Commun 1997; 727-34.

[24] Steiner T, Desiraju GR. Distinction between the weak hydrogen bond and the van der Waals interaction. Chem Commun 1998; 8912

Received: April 24, 2008

Revised: September 30, 2008

Accepted: September 30, 2008

(c) Wong et al.; Licensee Bentham Open.

This is an open access article licensed under the terms of the Creative Commons Attribution Non-Commercial License (http://creativecommons.org/licenses/by-nc/3.0/) which permits unrestricted, non-commercial use, distribution and reproduction in any medium, provided the work is properly cited. 